\title{
Targeting TBP-associated factors in ovarian cancer
}

\author{
Jennifer R. Ribeiro' , Lindsay A. Lovasco ${ }^{2}$, Barbara C. Vanderhyden ${ }^{3,4}$ and Richard N. Freiman ${ }^{1,2} *$ \\ 1 Pathobiology Graduate Program, Brown University, Providence, RI, USA \\ ${ }^{2}$ Molecular and Cellular Biology and Biochemistry, Brown University, Providence, RI, USA \\ ${ }^{3}$ Cellular and Molecular Medicine, University of Ottawa, Ottawa, ON, Canada \\ ${ }^{4}$ Centre for Cancer Therapeutics, Ottawa Hospital Research Institute, Ottawa, ON, Canada
}

\section{Edited by:}

Angeles Alvarez Secord, Duke

University Medical Center, USA

\section{Reviewed by:}

Naoko Tanese, New York University School of Medicine, USA

Victoria Lin Bae-Jump, University of North Carolina at Chapel Hill, USA

${ }^{*}$ Correspondence:

Richard N. Freiman, Molecular and Cellular Biology and Biochemistry, Brown University, 70 Ship Street, Providence, RI 02893, USA

e-mail: richard_freiman@brown.edu
As ovarian tumors progress, they undergo a process of dedifferentiation, allowing adaptive changes in growth and morphology that promote metastasis and chemoresistance. Herein, we outline a hypothesis that TATA-box binding protein associated factors (TAFs), which compose the RNA Polymerase II initiation factor, TFIID, contribute to regulation of dedifferentiation states in ovarian cancer. Numerous studies demonstrate that TAFs regulate differentiation and proliferation states; their expression is typically high in pluripotent cells and reduced upon differentiation. Strikingly, TAF2 exhibits copy number increases or mRNA overexpression in $73 \%$ of high-grade serous ovarian cancers (HGSC). At the biochemical level, TAF2 directs TFIID to TATA-less promoters by contact with an Initiator element, which may lead to the deregulation of the transcriptional output of these tumor cells. TAF4, which is altered in $66 \%$ of HGSC, is crucial for the stability of the TFIID complex and helps drive dedifferentiation of mouse embryonic fibroblasts to induced pluripotent stem cells. Its ovary-enriched paralog, TAF4B, is altered in $26 \%$ of HGSC. Here, we show that TAF4B mRNA correlates with Cyclin D2 mRNA expression in human granulosa cell tumors. TAF4B may also contribute to regulation of tumor microenvironment due to its estrogen-responsiveness and ability to act as a cofactor for NFKB. Conversely, TAF9, a cofactor for p53 in regulating apoptosis, may act as a tumor suppressor in ovarian cancer, since it is downregulated or deleted in $98 \%$ of HGSC. We conclude that a greater understanding of mechanisms of transcriptional regulation that execute signals from oncogenic signaling cascades is needed in order to expand our understanding of the etiology and progression of ovarian cancer, and most importantly to identify novel targets for therapeutic intervention.

Keywords:TAF2, TAF4, TAF4B, TAF9, TBP-associated factors, TFIID, differentiation, ovarian cancer

\section{INTRODUCTION}

Ovarian cancer is the most deadly reproductive cancer. Although progress has been made in understanding its etiology and progression, there has been no improvement in patient overall survival since the implementation of taxane-platinum therapy in the 1990s (1). For this reason, novel approaches are required to make headway in this challenging disease. Many researchers are taking advantage of the genomic data in the cBioPortal for Cancer Genomics assembled by The Memorial Sloan Kettering Cancer Center (MSKCC) to identify potential new targets for treatment, which has greatly contributed to our understanding of the complex genetic mechanisms governing ovarian cancer $(2,3)$. However, targeting specific oncogenic pathways can be challenging, since resistance develops due to activation of compensatory pathways (4). These signaling pathways converge on transcriptional control of genes that regulate differentiation, proliferation, and apoptosis, as well as other cancer cell properties including migratory and invasive potential, immune response, angiogenesis, telomere maintenance, and energy metabolism. Although not without challenges itself, investigating cell-type specific mechanisms of global transcriptional regulation, which may potentially be disrupted to halt or reverse tumor progression, could open up a new field of investigation in ovarian cancer research.

At the biochemical level, transcription is controlled by numerous core transcriptional complexes, such as TFIID, along with various cofactors. Studies in human cells and Drosophila initially revealed TFIID as an integral component of the core transcriptional machinery for RNA Polymerase II at mRNA encoding genes $(5,6)$, and demonstrated that it is composed of TATA-box binding protein (TBP) and multiple TBP-associated factors (TAFs) (7, 8). To date, 13-14 TAFs (9) and several tissue-specific variants (10) have been identified. In vivo genetic analyses unveiled a more complex role for TFIID in regulating tissue-specific and contextdependent transcriptional programs, demonstrating the existence of alternative TFIID complexes and tissue-specific TAFs (11-17). Three such complexes, which will be discussed in greater detail later in this manuscript, are illustrated in Figure 1. The realization that TFIID subunits regulate cellular processes in tissue-specific manners prompted research into TAF involvement in modulating tumor characteristics, including proliferation, differentiation, apoptosis, metastasis, and hormone response. The considerable variability seen in these reports, which are summarized in Table 1, 


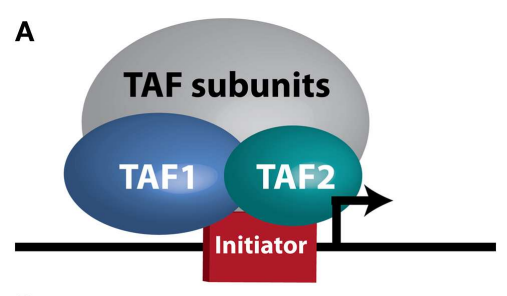

B

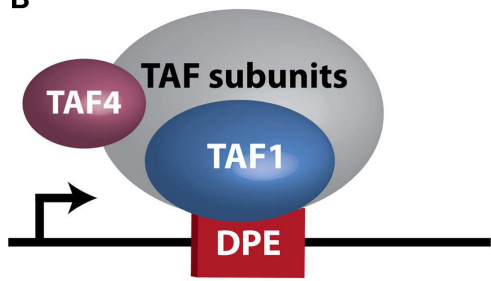

C

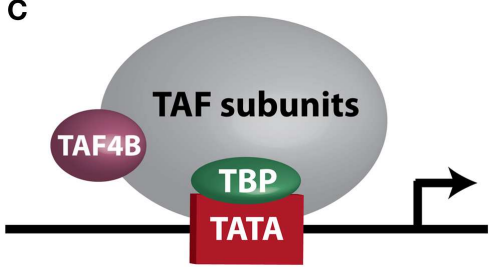

FIGURE 1 |TFIID sub-complexes. Arrows indicate transcription start site (A) A TAF1/TAF2 complex contacts Initiator at a TATA-less promoter. (B) TAF1 contacts a downstream promoter element (DPE) at a TATA-less promoter. TAF4 is also important for this interaction. (C) TAF4B substitutes for TAF4 in a TFIID complex bound at a TATA-box by TBP.

further supports the notion that the plasticity of the TFIID complex allows for variation in transcriptional control depending on cellular context. However, perhaps due to this plasticity, our understanding of the contribution of the TFIID complex to tumorigenesis and cancer progression remains limited.

While biochemical and genetic analyses point to a role for TFIID in regulating tumor-related phenotypes, the recent assembly of the cBioPortal for Cancer Genomics by MSKCC sheds further light on the subject. A bioinformatic analysis of 316 highgrade serous ovarian carcinomas (HGSC) whose copy number, mutational status, and mRNA levels are stored in the portal, reveals the TFIID complex as one of the most significantly altered subnetworks in this panel of tumors; TFIID alterations are detected in $42 \%$ of tumors by the study's analyses (49). Interestingly, when comparing the incidence of TAF copy number alterations (CNAs) and mutations between various tumor types, the HGSC set [The Cancer Genome Atlas (TCGA); provisional; all tumors] exhibits the most frequent alterations (59.8\%). The overwhelming majority of these alterations are amplifications (Figure 2A), supporting the argument that the TFIID complex is important in ovarian cancer. A closer look at specific TAF alterations in the HGSC set (TCGA; provisional; complete tumors = all tumors with CNAs, mRNA, and sequencing data) reveals TAF2 amplifications, copy number gains, and mRNA upregulation $(Z$-score $>+2.0)$ in $73 \%$ of tumors; TAF4 and TAF4B show these alterations in 66 and 26\% of tumors, respectively $(2,3)$ (Figure 2B). Other TAFs not depicted here are also frequently amplified. Conversely, homozygous deletions or mRNA downregulation $(Z$-score $<-2.0)$ of TAF9 are observed in $98 \%$ of complete tumors $(2,3)$ (Figure $2 B$ ), which is in accordance with TAF9's reported role as a cofactor for $\mathrm{p} 53$ and its involvement in promoting apoptosis $(44,45)$. As suggested by this TCGA data, as well as the studies outlined in Table 1, particular TAFs may regulate tumor properties in very precise and tissue-specific manners. Moreover, studies performed on the role of TAF subunits in development suggest that specific TAF subunits function as master regulators of differentiation and proliferation (11-13, 50-58), which has important implications for the process of dedifferentiation that occurs with tumor progression. Herein, we outline the potential for TAFs to regulate differentiation, proliferation, and apoptosis in ovarian tumors, and discuss the implications of this regulation for tumor cell-autonomous and microenvironment effects.

\section{MATERIALS AND METHODS \\ cBioPortal FOR CANCER GENOMICS}

The portal assembled by the MSKCC at http://www.cbioportal. org/public-portal/ was used for analysis of TAF alterations in ovarian cancer. To generate the cross-cancer alteration summary, "Mutation and CNA" data types were analyzed for "All Cancer Studies." TAF1, TAF2, TAF3, TAF4, TAF4B, TAF5, TAF6, TAF7, TAF8, TAF9, TAF10, TAF11, TAF12, TAF13, and TAF15 were input as the gene set to be analyzed. To examine alterations in individual TAFs, we queried "Ovarian Serous Cystadenocarcinoma" (TCGA, Provisional). One hundred fifty-eight "complete tumors" (those with copy number, mRNA expression, and sequencing data) were included. For TAF2, TAF4, and TAF4B, the following search was performed: DATATYPES: AMP GAIN EXP > 2.0; TAF2, TAF4, TAF4B, in order to view amplifications, copy number gains, and mRNA expression $(Z$-score $>2.0)$ for these TAFs. No mutations were present. Copy number data is putative and generated by GISTIC algorithm. Messenger RNA expression $Z$-scores were determined by RNA Seq Version 2 RSEM. Detailed information on the GISTIC algorithm and mRNA $Z$-scores can be found at http://www.cbioportal.org/public-portal/faq.jsp.

\section{ANIMALS}

All animal protocols were performed at Brown University. Mice were killed by carbon dioxide euthanasia, and all protocols were reviewed and approved by the Brown University Institutional Animal Care and Use Committee.

\section{SURGERIES AND LIVER COLLECTION}

Mouse hepatectomies were performed as described in Greene and Puder (59). Briefly, adult mice were anesthetized using insoflurane prior to surgery. Fifty percent hepatectomy consisted of ligature and removal of the left and left medial lobe through a midabdominal incision followed by suture of incision. Sham surgeries involved incision and manipulation of liver, without removal, followed by suture of incision. Mice recovered in cages on a $37^{\circ}$ warm plate during the hours following surgery. In the experimental mice, the left lobes were collected at $0 \mathrm{~h}$ ("removed"), and the right lobes were removed at the indicated timepoints ("recovered"). Total RNA was isolated for qRT-PCR analysis. 


\section{Table 1 | Summary of studies on TAFs in cancer.}

\section{TAF1}

- Frequent mutations in uterine serous carcinoma (18)

- Compensatory for androgen withdrawal in prostate cancer/co-activator for androgen receptor (19)

- Knockdown causes resistance to stress-induced apoptosis/reduces p27 (kip1) expression (20)

- Interacts with HPV protein E2 $(21,22)$. Overexpression in cervical cancer cells modulates E2-dependent transcription (21)

- Promotes MDM2 degradation of p53 (23). Promotes cell cycle progression by phosphorylating p53 and promoting its degradation (24)

- Histone acetyltransferase (HAT) activity of TAF1 is important for cyclin D1 transcriptional activation and cell cycle progression (25)

- TAF1 inactivation promotes DNA damage response and cell cycle arrest (26)

- TAF1/TAF2 binds TATA-less SRC promoters that have Initiator elements. Transcription from SRC promoters is TAF1-dependent, and the HAT activity of TAF1 partly regulates transcription from SRC promoters (27)

- Interacts with B-Myb and helps mediate activation of Myb-response genes, which regulate cell cycle (28)

- Bound by c-Jun, which increases TFIID-driven transcription by de-repressing TAF1 repression of TBP binding to TATA-boxes (29)

- Regulates transcription of cyclin A (30)

\section{TAF2}

- TAF1/TAF2 binds TATA-less SRC promoters with Initiator elements (27)

- Yeast TAF2 required for transcription of B-type cyclins and cell cycle progression (31)

\section{TAF4 and TAF4B}

- TAF4 inactivation in adult mouse epidermis causes epidermal hyperplasia, upregulation of EGF family mitogens, malignant transformation of DMBA-induced papillomas, and appearance of invasive melanocytic tumors in DMBA-treated mice (32)

- Estrogen upregulates TAF4B in mouse serous ovarian tumors (33)

- TAF4B identified as a hub gene in head and neck squamous carcinoma associated with radiosensitivity (34)

- TAF4B knockdown promotes migration of colon cancer cells in vitro by down regulation of the AP-1 target gene ITGa6 (35)

- TAF4B is a c-Myc target gene in human glioblastoma cells and human promyelocytic leukemia cells (36)

\section{TAF6}

- $72 \mathrm{kDa}$ isoform causes growth suppression of normal and transformed breast epithelial cell lines due to novel interaction with the G2 arrest protein GADD45a (37)

- $72 \mathrm{kDa}$ isoform forms a TFIID complex lacking TAF9; its elevated expression in Hela cells causes apoptosis, increased transcription of p21 and GADD45, and decreased MDM2 transcription (38)

- TAF6 and TAF9 necessary for transcriptional activation by p53 (39)

\section{TAF7 and TAF7L}

- TAF7 knockdown in androgen-independent prostate cancer cells reduces polyamine transport and causes resistance to methylglyoxalbisguanylhydrazone (MGBG)-induced apoptosis (40)

- TAF7 is a co-activator for the mitogen C-JUN in HEK293 and COS cells (41)

- TAF7L downregulated in $59 \%$ of male patients with acute myeloid leukemia (42)

\section{TAF9}

- Disruption of interactions between Hedgehog transcription factors (Gli proteins) and TAF9 reduces Gli/TAF9-dependent transcription, suppresses cancer cell proliferation, and reduces xenograft growth (43)

- UV and IR disrupts hydrogen bonding between Thr18 and Asp21 on p53, reducing MDM2 binding to p53 and allowing recruitment of p53 co-activator, TAF9 (44)

- TAF9 inhibits MDM2-mediated degradation of p53/acts as a co-activator of p53 (45)

- 72 kDa TAF6 isoform forms a TFIID complex lacking TAF9/its elevated expression in Hela cells causes apoptosis, increased transcription of p21 and GADD45, and decreased MDM2 transcription (38)

- TAF6 and TAF9 necessary for transcriptional activation by p53 (39)

- TAF9 is a crucial co-activator for p53 (46)

TAF10

- Stimulates transcription from ERE-containing promoters (47)

\section{TAF12}

- Upregulated in colon cancer cell lines with RAS mutations or overexpression of mutant RAS; knockdown destabilizes TFIID; and enhances E-cadherin levels, thereby reducing migration/adhesion of RAS transformed cells with EMT (48)

\section{HUMAN GRANULOSA CELL TUMORS}

Samples of human granulosa cell tumors (GCTs) were obtained from the Ottawa Ovarian Cancer Tissue Bank, with consent from the patients and under a protocol approved by The Ottawa
Hospital Research Ethics Board (1999540-01H). Frozen tissues were homogenized in RLT buffer using an IKA Ultra-Turrax homogenizer and total RNA was extracted using the Qiagen RNeasy Mini Kit as per the manufacturer's protocol. 
A

Cross-Cancer Alteration Summary for

TAF1, TAF2, TAF3, TAF4, TAF4B, TAF5, TAF6, TAF7, TAF8, TAF9, TAF10, TAF11, TAF12, TAF13, TAF15

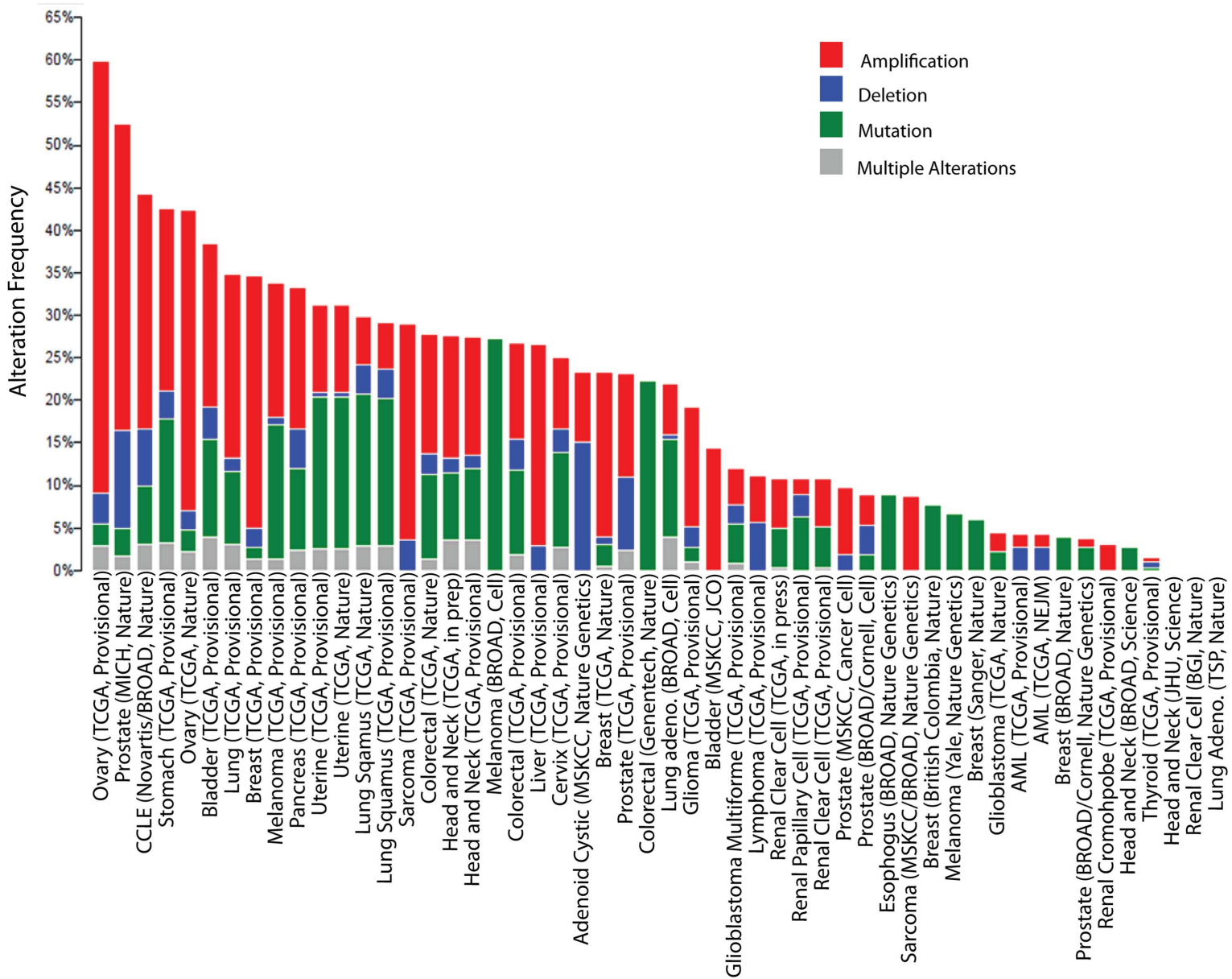

B TAF alterations in high-grade serous ovarian cancer

158 complete tumors (tumors with copy number alteration, mRNA and sequencing data)

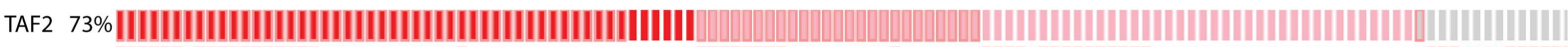

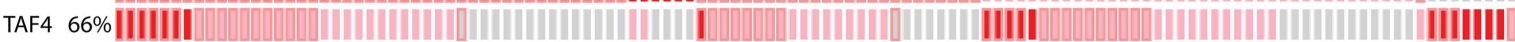

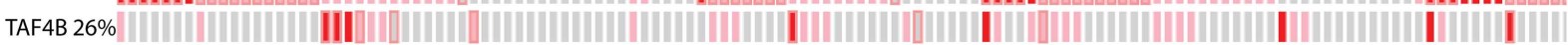

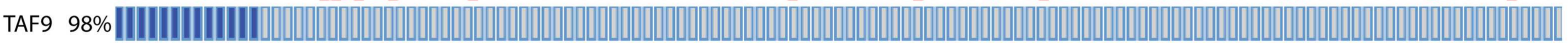

Amplification Gain [mRNA upregulation Homozygous Deletion [ mRNA downregulation

FIGURE 2 |TBP-associated factor alterations in high-grade serous ovarian cancer (HGSC). (A) Cross-cancer summary of copy number alterations and mutations in TAFs for all cancer sets in the cBioPortal for Cancer Genomics (2, 3). (B) Amplifications, copy number gains, and mRNA upregulation of TAF2, TAF4, and TAF4B, and deletions and mRNA downregulation of TAF9, in the cBioPortal HGSC set (TCGA, provisional, complete tumors) (2, 3). These "oncoprints" are partial views of alterations in 158 complete tumors. Alterations are present in 158 complete tumors in the percentages noted on the left.

\section{QUANTITATIVE RT-PCR}

cDNA was prepared from $1 \mu \mathrm{g}$ total RNA, and qRT-PCR performed as previously described (33). Data was analyzed using the $\Delta \Delta \mathrm{Ct}$ method and normalized to $18 \mathrm{~s}$ rRNA. Correlation between TAF4 or TAF4B and CCND2 was determined by Pearson Correlation Co-efficient (R). $P$-values were determined by two-tailed, unpaired Student $t$-test. Primers used are as follows:
Mouse Tafa4 F - ATC TCC ACT GTG CAG GCTT CC Mouse Taf4a R - GGT CAG CTG CCG TGC AAT A Mouse Taf4b F - GAT GTT ACT AAA GGC AGC CAA GAG T Mouse Taf $4 b$ R - CTG CTC TGG ATC TTC TTT ATT GGA G Human TAF4 F - CTC AGA ACC CGA CCA ACA TCC Human TAF4 R - CTT CGG ACG AGG ACC ATT CC Human TAF4B F - ATC CAG TTT CCT GCT AAT TTG C Human TAF4B R - CCA ACA TCA ACG GAC CAC TGT 


\section{Human CCND2 F - CCG ACA ACT CCA TCA AGC CT \\ Human CCND2 R - AGCACCACCAGTTCCCACTC \\ 18s rRNA F - CCG CGG TTC TAT TTT GTT GG \\ 18s rRNA R - GGC GCT CCC TCT TAA TCA TG}

\section{ANTIBODIES AND WESTERN BLOT ANALYSIS}

Mouse ESC protein extracts pre- and post-retinoic acid (RA)induced differentiation were generously provided by the Fairbrother lab (Brown University) and prepared as described in Tantin et al. (60). Western blot analysis was performed as previously described (33). Antibodies used are as follows: (1) TAF II p250 (1:200; sc-17134; Santa Cruz); (2) mouse monoclonal anti-TAF(ii)135 (1:250; 612054; BD Transduction Laboratories); (3) polyclonal rabbit anti-mouse TAF4B [1:250; raised against amino acids $1-98$ (N-terminus/co-activator domain) of mouse TAF4B (33, 61, 62)]; (4) TBP (ab818; Abcam); (5) rabbit anti $\beta$-tubulin (1:200; RB-9249-P; Thermo Scientific).

\section{TFIID AS A DIRECT REGULATOR OF CELLULAR DIFFERENTIATION STATES}

Throughout ovarian tumorigenesis and progression, tumor cells undergo multiple requisite changes in morphology and phenotype (Figure 3). The ovarian surface epithelium (OSE) undergoes metaplasia to a fallopian tube epithelial morphology early in serous adenocarcinoma formation (63) and is associated with an increase in E-cadherin expression as the mesothelial OSE obtains the columnar epithelial phenotype of the fimbrial epithelium (63). The process of metaplasia is controversial as evidence has accumulated that many HGSC develop from fimbrial epithelial cells that become lodged in the ovarian stroma (64). However, convincing arguments still exist for OSE metaplasia, including the fact that the process can be replicated in mouse and hen models of ovarian cancer $(63,65-70)$. The initial origin of the tumor becomes less important as it progresses from a well-differentiated papillary histology to a dedifferentiated morphology. This process of dedifferentiation from an organized morphology resembling the tissue of origin to a disorganized mass of less differentiated cells is a hallmark of cancer progression in diverse tissues (71-74), and is defined by a grading system set forth by the International Federation of Gynecology and Obstetrics (FIGO) (75). Poorly differentiated tumors are associated with a worse prognosis (76-79) since dedifferentiation allows adaptive changes in morphology that promote invasion and metastasis (71). Thus, tumor dedifferentiation is closely associated with the process of epithelial-to-mesenchymal transition (EMT), whereby loss of epithelial differentiation allows cells to acquire productive characteristics, such as invasion and migratory capabilities (80). In ovarian cancer, dedifferentiated tumors

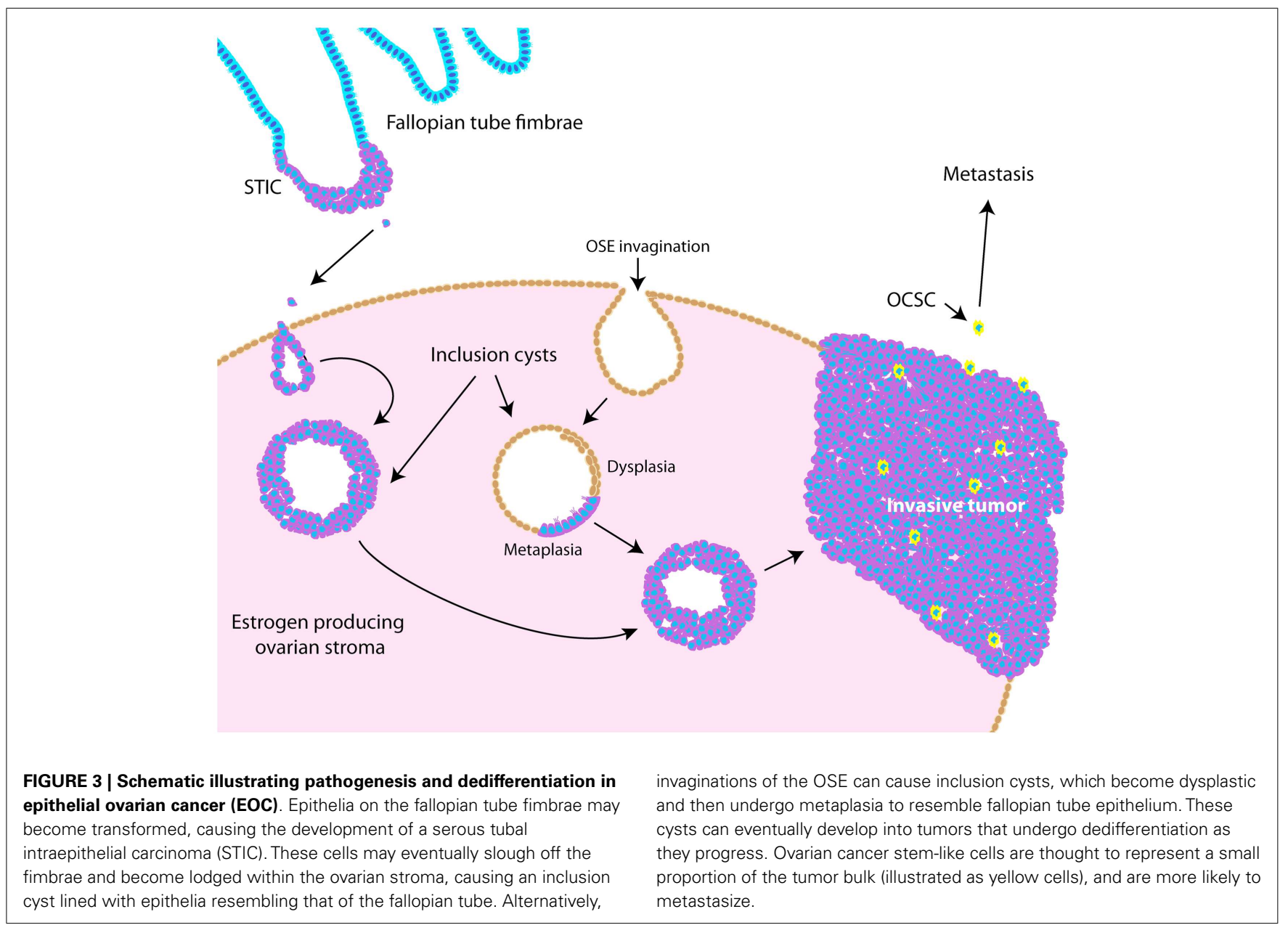


manifest as a solid tumor mass, lacking the glandular morphology seen in well-differentiated serous ovarian tumors (81). Accordingly with loss of epithelial morphology, E-cadherin expression is frequently reduced in dedifferentiated tumors, ascites, and metastases (72, 82-84). In dedifferentiated tumors where E-cadherin is not lost, other adhesion complex components, such as the catenins, could be disrupted $(85,86)$. Collectively, these studies show that ovarian tumors undergo complex morphological and functional changes from their initiation to progression.

Ovarian cancer stem-like cells (OCSCs) represent a very small percentage of tumor cells and are considered a dedifferentiated, or pluripotent, cell-type. Accordingly, CSCs are characterized by upregulation of mRNAs encoding stem cell markers, including OCT4, SOX2, stem cell factor receptor (C-KIT), NOTCH1, ABCG2, BMI1, and NES (Nestin) (87) and NANOG protein levels (88). Functionally, CSCs can recapitulate the original tumor, form xenografted tumors at limiting dilutions, are resistant to chemotherapy, form spheroids in culture, and have increased invasive and migratory potential (89). OCSCs have been shown to be enriched for CD $44^{+} / \mathrm{CD} 117(\mathrm{C}-\mathrm{KIT})^{+}$cells $(87,90)$, CD $44^{+} / \mathrm{CD} 24^{-}$cells $(91)$, and CD $44^{+} / \mathrm{MyD}^{+} 8^{+}$cells $(90)$. More recently, ALDH1 and CD133 have been identified as markers for OCSCs (92-94). Nonetheless, it is challenging to study this population of cells since it represents such a small percentage of the tumor mass. Since dedifferentiated tumors are further along the path toward pluripotency, perhaps CSCs represent a small proportion of cells that are furthest along that path. In support of this notion, Gabbert et al. noted that the "invasion front" of colon carcinomas was marked by a loss of differentiation, and that in already undifferentiated colon carcinomas, only subtle changes were required for the invasive phenotype (71). While it is clear that tumors undergo these various dedifferentiation processes throughout tumorigenesis and progression, the precise molecular events regulating metaplasia, dedifferentiation, EMT, and the establishment of OCSCs are not well-understood. Understanding these mechanisms is essential if we hope to identify treatments that inhibit or reverse these processes.

The importance of TAFs in regulation of normal differentiation processes during development has been well-established in recent years. One of the first studies to indicate the involvement of TAFs in differentiation shows a reduction in TAF4 expression in embryonic cortical neuronal stem cells that differentiate down a neuronal, but not a glial differentiation pathway (50), suggesting that specific TAFs are involved in particular differentiation pathways. Comparatively, TAF10 is essential for the differentiation of keratinocytes, but is dispensable in adult epidermis (51), and is also required for proliferation of undifferentiated embryonic carcinoma cells, but not after in vitro differentiation of these cells by RA (95). These two studies establish the importance of specific TAFs in regulating proliferation and differentiation of progenitor, but not differentiated cell-types. In parallel, knockdown of TAF1 and TAF4B in primary mouse embryonic maxillary mesenchymal cells reduces proliferation and causes deregulation of osteogenic differentiation (52). In liver, lower levels of TBP and TAFs are seen in hepatocytes compared to differentiated hepatoblasts and TAF4 and TBP are reduced upon in vitro induced hepatogenesis (53). These results are in agreement with the typically low levels of TAF4B detected in adult liver that we have previously reported (17). Accordingly, we saw an increase of Taf $4 b$, but not Taf $4 a$ (the mouse homolog of human TAF4), mRNA upon liver regeneration induced by partial hepatectomy, suggesting that this specific TAF subunit may be involved in regulating either hepatocyte re-entry into the cell cycle or differentiation of liver stem cells (Figure 4A). Collectively, these studies generally reveal a reduction of TAFs as
A

Taf $4 a$ and Taf $4 b$ mRNA Expression

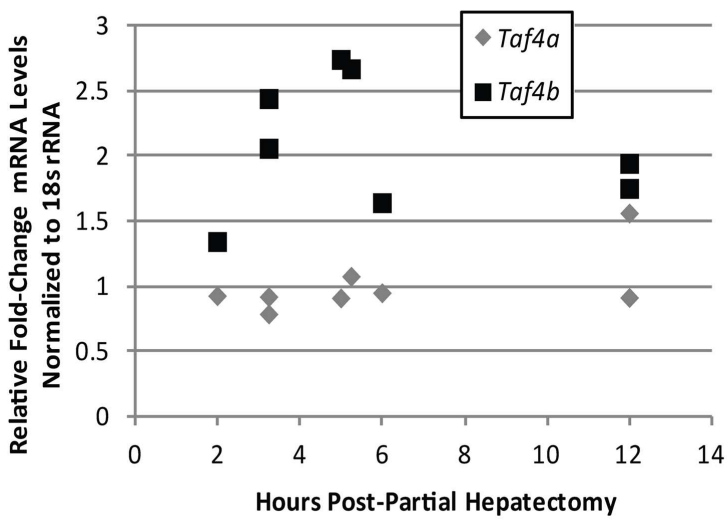

B

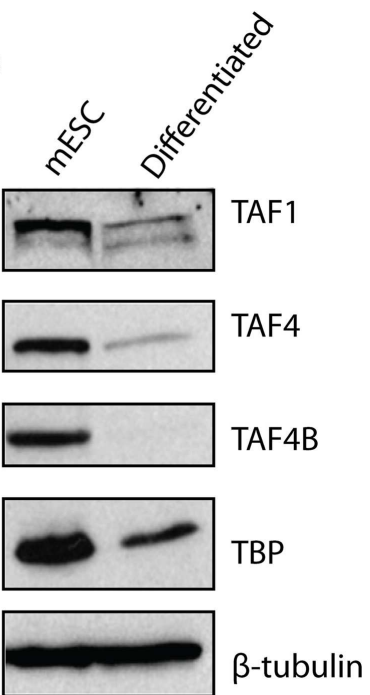

FIGURE 4 | TBP-associated factor subunits are dynamic during differentiation and proliferation. (A) Quantitative RT-PCR analysis of Taf4a and Taf4b in normal (removed) and partial hepatectomy (recovered) mouse livers. Data represented as fold-increase (recovered/removed) plotted against hours post-hepatectomy. (B) Western blot analysis of TAF1, TAF4, TAF4B, and TBP in mouse embryonic stem cells pre- and post-retinoic acid-induced differentiation. $\beta$-tubulin was used as a loading control. 
cells progress from a pluripotent to a differentiated state, suggesting their importance in regulating this process or in maintenance of pluripotency.

TBP-associated factors can act outside of the canonical TFIID complex to regulate differentiation as well. Deato et al. show that an alternate TFIID complex consisting of TAF3 and TBP-related factor 3 (TRF3) is required for activator-dependent transcription of myogenin and differentiation of myoblasts to myotubes. Importantly, expression of other TFIID subunits typically believed to be essential for TFIID function, including TAF1, TAF4, and TBP, is lost with myoblast differentiation (11-13). Moreover, higher levels of TAF3 are reported in mouse embryonic stem cells (mESCs) compared to mouse embryonic fibroblasts (MEFs), adult spleen, lung, heart, brain, and liver. In a study by Liu et al., TAF3, along with the pluripotency factor OCT4, are reduced upon mESC differentiation, accompanied by slight reductions in TAF4 and TBP. Confirming the importance of TAF3 in mESC differentiation, when TAF3 is knocked down in plated embryoid bodies, the cells lose pluripotency, and largely differentiate to neurons. Interestingly, the authors identify a TFIIDindependent transcriptional regulatory role for TAF3, which works in conjunction with CCCTC-binding factor (CTCF) and cohesin to regulate transcription of endoderm-specific gene expression programs (54).

The TAF4 and TAF4B subunits of TFIID are also known to support pluripotency. Bahat et al. recently reported that the TAF4 paralog TAF4B is highly expressed in mESCs and is downregulated upon differentiation (55). We have independently observed the reduction of TAF1, TAF4, TAF4B, and TBP upon in vitro differentiation of mouse embryonic stem cells by RA (Figure 4B). Moreover, the Bahat et al. study reveals that TAF4B knockdown decreases mESC self-renewal, differentiation, and cell cycle progression, along with a reduction in genes that are also reduced upon RA-induced mESC differentiation. Conversely, they report TAF4 knockdown to increase proliferation and prevent RA-induced differentiation (55), suggesting functional differences between these paralogs in mESCs. Mengus et al. report an increase in serumindependent autocrine growth upon TAF4 knockdown in MEFs, which they attribute to compensation by TAF4B (56), suggesting some functional overlap between these paralogs. However, like Bahat et al. they also show that there are differences between TAF4 and TAF4B in MEFs, as illustrated by deregulation of over 1,000 genes in the TAF4 knockdown cells that are not compensated for by TAF4B (56). Although these studies approach TAF knockdowns from opposite ends of the differentiation spectrum, they both reveal interesting information about the differences and similarities between TAF4 and TAF4B, and point to a role for these TAFs in regulating the balance of differentiation and/or proliferation.

Some of the results of the Bahat et al. study regarding TAF4 are in contrast to a related study by Pinjappel et al., in which the authors show that knockdown of TAF1, TAF3, TAF4, TAF4B, TAF5, TAF6, TAF9, TAF11, TAF12, and TAF13 each results in differentiation of mESCs, but does not affect proliferation or apoptosis (57). TAF5 knockdown alone decreases transcription of pluripotency genes, increases transcription of differentiation markers, and decreases OCT4/NANOG binding at the TAF4 promoter, pointing to transcriptional activation of TAF4 as essential in maintaining stemness. Overexpression of TAFs during OCT4/SOX2/KLF4/MYC (OSKM) reprograming of MEFs increases mESC morphology, while omission of TAF4 from the overexpressed complex abolishes its stimulatory effect on reprograming. Eventually, it was found that TAF4 alone promotes the reprograming of MEFs to induced pluripotent stem cells (iPSCs), highlighting the importance of this individual TAF in promoting cellular reprograming to a dedifferentiated state (57). However, the main discrepancy between these studies - TAF4 knockdown increasing proliferation and preventing differentiation of $\mathrm{mESC}$ versus TAF4 knockdown not affecting proliferation yet promoting differentiation of $\mathrm{mESC}$ - needs to be addressed. Interestingly, alternative TAF4 isoforms could play a role in modulating differential functions of TAF4. Kazantseva et al. show that expression of TAF4 isoforms with structural modifications of the TAF4-TAFH (co-activator) domain increases during differentiation of human mesenchymal stem cells, while silencing of TAF4-TAFH intact isoforms causes cell cycle arrest and blocks specific differentiation pathways (58). Moreover, the expression of the TAF4-TAFH deletion isoforms is also cell-type specific, with one of them (TAF4_v4) being expressed only in the ovary, placenta, stomach, testis, and thymus (58). This study highlights another layer of complexity to transcriptional regulation by TAF subunits that is introduced by alternative splicing events, and also suggests the importance of taking a tissue-specific approach to studying this regulation.

While the contribution of TAFs to ovarian proliferation and differentiation has not been well-investigated, these studies support the general notion that certain core TAFs are reduced upon differentiation. It is not clear whether other differentiation signals cause the downregulation of TAFs, or the downregulation of TAFs promotes differentiation signals; however, a productive feed-forward loop likely exists between TAF subunits and OSKM factors, as suggested by Pijnappel et al. Regardless, it is apparent that TAFs play an important role in maintenance of pluripotency and cause dedifferentiation when overexpressed in differentiated cells. It is also clear that diverse TAFs function to regulate differentiation in tissue-specific manners, highlighting the importance of expanding these studies to include the ovary, and potentially other tissues. In relationship to cancer, TAF regulation of differentiation state could be important as tumors dedifferentiate as a whole, or as individual cells take on a more "pluripotent" phenotype and become CSCs. Figure 5 illustrates a potential model for TAF regulation of differentiation and proliferation as it pertains to development and ovarian tumor progression. As outlined here, we hypothesize that deregulation of TAF expression, such as what occurs with amplifications commonly seen in HGSC, contributes to tumor dedifferentiation or establishment of OCSCs.

\section{TAF REGULATION OF TUMOR-RELATED PHENOTYPES}

The contribution of individual TAFs to tumor dedifferentiation as well as diverse tumor properties and their microenvironment needs to be considered. For the sake of this discussion, we will focus on TAF2, TAF4, TAF4B, and TAF9 as illustrative examples of how specific TAF subunits may be involved in regulating ovarian tumor properties. TAF2 appears to be important in ovarian cancer since it is most frequently altered in HGSC, with amplifications, copy number gains, and mRNA upregulation present in 


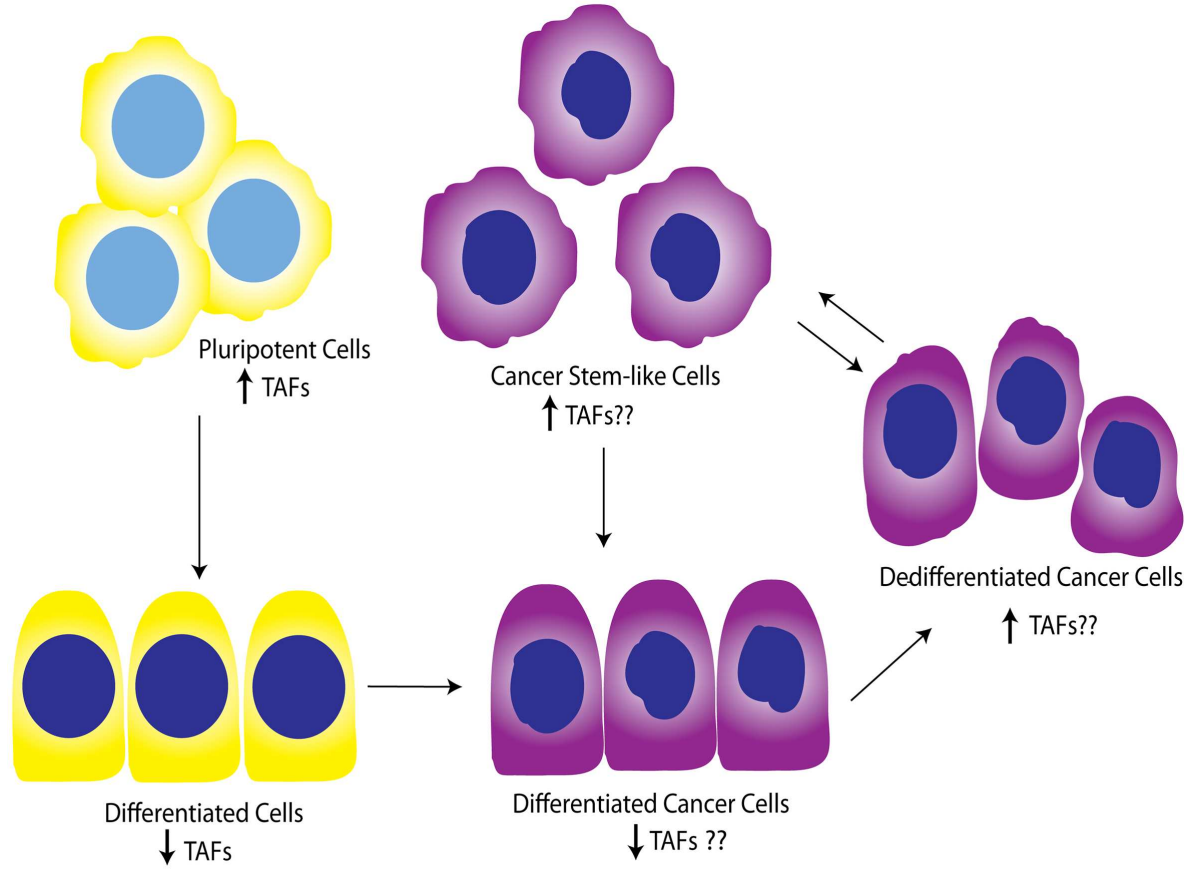

FIGURE 5 |Working model for TAF involvement in differentiation during development and tumor progression. Studies show that TAFs are downregulated in differentiated cells compared to pluripotent cells. This model illustrates the hypothesis that TAFs are also expressed at lower levels in differentiated cancer cells, but may be upregulated as these cells progress to dedifferentiated cells or pluripotent cancer stem-like cells. Yellow, normal cells; purple, cancer cells.

$73 \%$ of tumors $(2,3)$. Although little is known about the role TAF2 might play in cancer, it is required for cell cycle progression in yeast, and expression of yeast TAF2 and several other TAFs is dramatically reduced when cells are induced into a stationary phase (31). From a biochemical standpoint, the TAF1/TAF2 complex recognizes Initiator (Inr) elements (96), the relevance of which becomes apparent when examining another study showing that TATA-binding defective TFIID can still initiate transcription from TATA-containing or TATA-less promoters that have an Inr sequence (97). Although this study utilized a mutant TBP that was still capable of binding TFIID (97), a study by Wright et al. investigating the stability of the TFIID complex in Drosophila shows that TBP knockdown does not affect the stability of the TFIID complex, suggesting that TBP is not strictly required for TAF assembly (98). Figure 1A illustrates a TBP-free TFIID sub-complex (TFTC) (99) that could be responsible for TAF1/TAF2 regulation of transcription from Inr consensus sequences. Importantly, the set of genes containing an Inr sequence overlaps with, yet is distinct from, those bound only by non-defective TFIID (97), suggesting that a distinct transcriptional profile could exist in TAF2-overexpressing cells. In support of this notion, Dehm et al. demonstrate that the TAF1/TAF2 complex binds C-SRC $5^{\prime}$ exon promoters, which are TATA-less and contain Inr sequences (27). Interestingly, $C$ $S R C$ overexpression and activation are reported in ovarian cancer $(100,101)$ and contribute to activation of growth factor signaling cascades $(102,103)$ and anti-estrogen resistance (100). Given these results, it is possible that TAF2 overexpression could increase transcription of $C-S R C$ in some ovarian tumors.
Reminiscent of the TFIID-independent function of TAF3 in regulation of myogenesis (11-13), the transcriptional control of Inr-containing promoters by TAF1/TAF2 may be relevant in ovarian cancer, since TBP is predominantly downregulated in many HGSCs $(2,3)$. Incidentally, reliance on TBP-independent TAF functions is one potential reason for this unexpected downregulation of TBP; another could actually be mutation of p53 in HGSC, since TBP is known to bind and derepress p53 (104). Interestingly, TAF1 is not commonly deregulated in HGSC, although its role as a tyrosine kinase and regulator of cell cycle and apoptosis in other tissues is well-described (19-21, 23-25, 30, 105-107), and it is also frequently mutated in uterine serous carcinoma (18). The apparent tissue-specific effects of TAF1 reiterate the importance of studying individual TAFs in tissue-specific contexts. Further dissection of the role TAF2 plays in ovarian cancer could illuminate whether this TAF regulates alternative transcriptional programs involved in differentiation and proliferation.

After TAF2, TAF4 is the most frequently amplified and overexpressed TAF in HGSC $(2,3)$. We have already discussed its role in driving MEF dedifferentiation to iPSC (57), suggesting it could be a major regulator of dedifferentiation/pluripotency in certain contexts. From a molecular standpoint, TAF4 is interesting for several other reasons as well. In Drosophila, it is the most crucial subunit for maintaining the stability of the holo-TFIID complex, with TAF5, TAF6, TAF9, and TAF12 also contributing to this core complex. RNAi-mediated knockdown of TAF4 or TAF12, which dimerize via their histone-fold domains (HFDs), results in degradation of most of the other TAF subunits (98). Interestingly, TAF1, 
TAF2, and TAF11 are less critical (98), which is in support of the idea that a TAF1/TAF2 complex may initiate transcription as part of a TFIID sub-complex at Inr elements. Likewise, TAF1 and TAF4 are important for directing transcription from TATA-less, downstream promoter element (DPE)-containing promoters (98) (Figure 1B), while TATA-containing promoters are less dependent on these subunits. This evidence suggests that disruption of TAF4's HFD interaction with the HFD of TAF12 could potentially destabilize both holo-TFIID and many TFIID sub-complexes. The overexpression of many TAFs in HGSC discussed previously raises the possibility that inhibition of TFIID-driven transcription, such as might be possible using small molecule inhibitors, could reduce expression of a large set of genes potentially important for ovarian tumor growth and differentiation. However, compensation by alternative TFIID complexes might instead drive some level of transcription under these circumstances, including a complex containing the TAF4 paralog TAF4B, which is depicted in Figure 1C.

TAF4B is not as frequently altered in ovarian cancer, but nonetheless exhibits amplifications, copy number gains, or mRNA upregulation in $25 \%$ of $\operatorname{HGSC}(2,3)$. TAF4B is relevant to the discussion of TAFs in ovarian cancer because its expression is enriched in the ovary compared to other tissues, and it is required for proper ovarian follicle development and murine fertility (17, $61,62,108)$. In addition to oocyte and folliculogenesis defects in the Taf $4 b$-null ovary, granulosa cell proliferation and survival are dependent upon TAF4B expression (62). It is still not clear, however, whether adult Taf $4 b$-deficient ovarian defects are established during early development or occur due to signals from defective oocytes that remain into early adulthood in the Taf $4 b$-deficient ovary. Likewise, the precise contributions of germ cell versus somatic factors are not well-understood. Studies are underway to elucidate the mechanisms underlying the Taf $4 b$-null infertile phenotype. It is clear, however, that TAF4B plays a role in regulating proliferation in some contexts. The gene for Cyclin D2, a key cyclin that selectively regulates both normal granulosa cell and GCT proliferation (109), was identified as a transcriptional target of TAF4B by chromatin immunoprecipitation (ChIP) of TAF4B at the Ccnd2 promoter in TAF4B-overexpressing rat spontaneously immortalized granulosa cells (SIGCs) (110). In human GCTs, TAF4B mRNA expression strongly correlates $(R=0.93)$ with expression of CCND2, while TAF4 was found to only weakly correlate to CCND2 levels ( $R=0.32$; Figure 6). These data suggest that TAF4B regulation of this granulosa cell cyclin could play a role in GCT proliferation. Other genes linked to ovarian cancer were also identified as TAF4B targets in TAF4B-overexpressing SIGCs, including $c$-Jun, matrix metalloproteinase-3 (Mmp-3), and Fibronectin-1 (Fn1) (110). The preferential regulation of these genes by TAF4B over TAF4 could be due to a slight alteration in conformation of TAF4B-containing TFIID complexes compared to TAF4 alone containing complexes, which can affect promoter occupancy of specific genes, as identified by Liu et al. for c-Jun (111).

In further support of a potential role for TAF4B in GCT, we have recently found that TAF4B is upregulated by estrogen in normal mouse granulosa cells (33). Since estrogen signaling could contribute to GCT pathogenesis (112), perhaps TAF4B is an effector

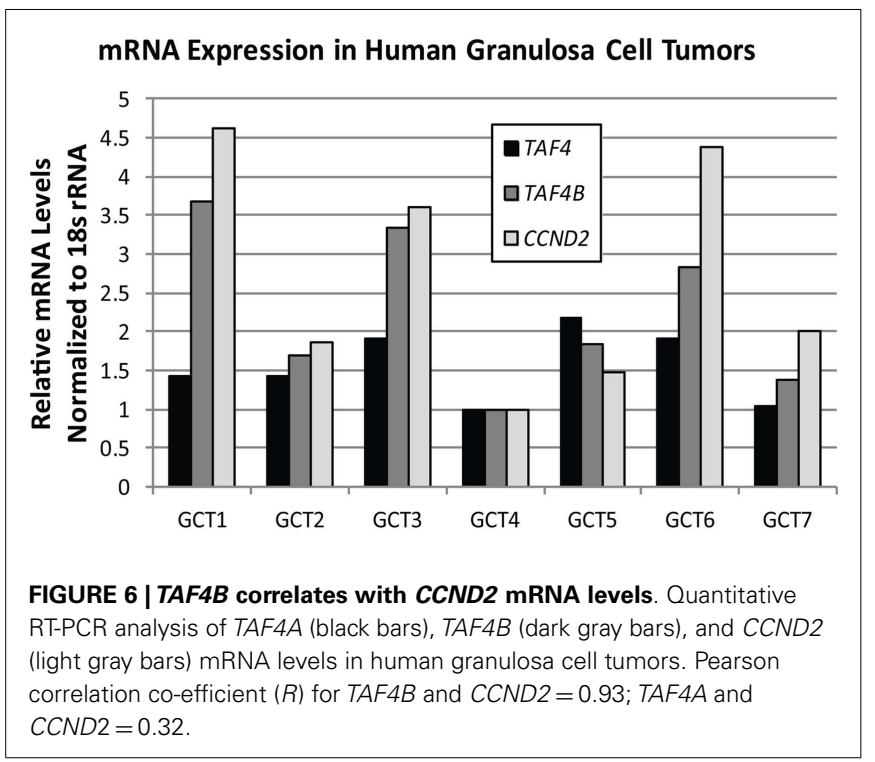

of certain aspects of estrogen signaling in GCT. Execution of estrogen-dependent effects by TAFs is not without precedence, as TAF10 was found to be important for efficient transcription at ERE-containing promoters in MCF7 breast cancer cells (47). From these data showing TAF4B involvement in estrogen signaling, granulosa cell proliferation, and regulation of a cell cycle protein, it seems likely that it could play a role in GCT; since granulosa cells also support epithelial ovarian cancers (EOC) as the microenvironment in which inclusion cysts arise, we will also discuss its potential involvement in EOC pathogenesis.

One long standing hypothesis for how the ovarian milieu contributes to ovarian cancer growth is hormonal signaling within the ovary, especially estrogen signaling. The granulosa cells are the estrogen producing cells in the ovary, and could support tumorigenesis from inclusion cysts, whether the cysts arise from the OSE or fimbrial epithelium. Studies report the stimulatory effects of estrogen on OSE hyperplasia (113) and metaplasia (114) as well as the more rapid establishment of serous ovarian tumors by SV40 Large T-antigen driven transformation of the OSE upon exposure to exogenous estrogen (66). In support of these experimental studies, epidemiological studies show that women who have been on long-term estrogen hormone replacement therapy have a greater risk of developing ovarian cancer (115-120). Our recent study finding TAF4B to be upregulated by estrogen in granulosa cells also reports dramatic upregulation of TAF4B in estrogen-supplemented mouse tumors (33). It is not clear, however, whether the upregulation of TAF4B in these tumors occurs in the OSE-derived cells (suggesting cell-autonomous effects) or in the tumor stroma (suggesting microenvironment effects). Either of these scenarios is possible, since we see TAF4B expression in both OSE and fimbrial epithelium in addition to the granulosa cells. Moreover, while TAF4B is normally regulated by $\mathrm{ER} \beta$ in granulosa cells, it can also be regulated by $\mathrm{ER} \alpha$ in the absence of $\operatorname{ER} \beta$ (33). Collectively, these results do not exclude either a cell-autonomous or microenvironment role for TAF4B in EOC. 
Another scenario exists whereby TAF4B could regulate the ovarian microenvironment to promote tumorigenesis. TAF4B was originally identified as a TFIID subunit in B-cells (14) and promotes expression of anti-apoptotic genes by acting as a co-

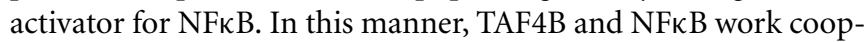
eratively to suppress tumor necrosis factor- $\alpha$ (TNF $\alpha)$-mediated apoptosis in 293 cells in vitro and in B- and T-cells in mice $(121,122)$. While this mechanism has not been investigated in the ovary, it could represent another way that TAF4B contributes to regulation of the immune microenvironment and protection from apoptosis, particularly in ovarian tumors with constitutively activated NFKB signaling. Such constitutive activation occurs in ovarian cancer due to the chronically inflamed microenvironment (123), resulting in enhanced growth and protection from apoptosis (112). Interestingly, NFKB activation may also be a hallmark of OCSCs and contribute to their escape from apoptosis. Alvero et al. show that CD $44^{+} / \mathrm{MyD}^{+} 8^{+}$cells have constitutive activation of $\mathrm{NF} K \mathrm{~B}$, and when treated with paclitaxel or $\mathrm{TNF} \alpha$, upregulate $\mathrm{NF} \kappa \mathrm{B}$ signaling instead of undergoing apoptosis (90). It will be interesting to determine if TAF4B also contributes to this NFKB-mediated protection of OCSCs.

While TAF4B could potentially be involved in mediating antiapoptotic effects, TAF9 is illustrative of a TAF acting as a putative tumor suppressor, since it is downregulated or deleted in $98 \%$ of HGSC. In support of this role, TAF9 is known to be a co-activator for p53 (44-46), which is ubiquitously mutated and downregulated in HGSC (2, 3). TAF9 physically interacts with p53 at its $\mathrm{N}$-terminus, where p53 also interacts with its negative regulator, MDM2, thereby inhibiting MDM2 degradation of p53. Functionally, this interaction translates to an increase in p53-induced cell cycle arrest or apoptosis, as demonstrated by fibroblast growth arrest following TAF9 overexpression, UV-induced association of p53 with TAF9 (45), and TAF9induced apoptosis of neuroendocrine tumor cells deprived of nerve growth factor (124). The pro-apoptotic role of TAF9 is illustrative of the complexity of regulation by TAFs and the multitude of effects that are likely species-, cell-type-, and contextdependent; i.e., while knockdown of TAF9 affects differentiation of mESCs (57), TAF9 can also regulate apoptosis in different contexts $(44,45)$. It will be important to determine if the downregulation of TAF9 in HGSC is a consequence of TP53 mutations, or if alterations in TAF9 are observed in other subtypes of EOC, which lack the hallmark p53 mutation of HGSC $(125,126)$.

As discussed in this section, individual TAFs have the potential to regulate tumor properties by a variety of mechanisms. This may include regulation of differentiation, as discussed in the previous section, or could also involve cell cycle effects, apoptosis or metastasis. The contribution of TFIID stability, presumably regulated by histone-fold dependent association of TAF4 and TAF12, as well as the contribution of putative TFIID sub-complexes that lack TBP or other subunits, merit investigation in the context of ovarian cancer. These complexes could have important roles in translating signals from upstream oncogenic cascades that are deregulated in ovarian cancer, including those regulating proliferation and differentiation.

\section{CONCLUSION}

Herein, we have outlined a hypothesis that TAF subunits, because of their documented importance in dedifferentiated cell-types and loss of their expression occurring with differentiation, also play a functional role in driving tumor dedifferentiation. TFIID, and TAF2, TAF4, TAF4B, and TAF9 in particular, are under-explored as potential contributors to the dedifferentiation process, and could also contribute to regulation of proliferation and apoptosis. Measuring levels of TAF subunits throughout tumor initiation and progression could reveal if they are modulated according to the differentiation state of the tumor. In addition to testing the role of TAFs in the differentiation of ovarian cell-types, differences between GCT versus EOC and cell-autonomous effects versus microenvironment effects should be explored.

It is crucial to investigate new areas in ovarian cancer, especially avenues that target processes downstream of oncogenic signaling cascades. Indeed, in yeast, approximately $84 \%$ of genes require one or more TAFs for their expression (127), supporting the notion that tumor characteristics could heavily rely on proper TAF functioning. Perhaps disruption of this function could be used as part of combinatorial therapy in ovarian cancer. However, research will also need to be done to investigate adaptive transcriptional mechanisms that could circumvent the reduction of TAF activity. Furthermore, the TAFs associated with RNA polymerase I and III TBP-containing general transcription complexes could also be relevant to the study of ovarian cancer $(128,129)$, since these other polymerases directly promote cellular growth (130). We conclude that a greater understanding of mechanisms of transcriptional regulation that carry out signals from oncogenic signaling cascades is needed in order to expand our understanding of the etiology and progression of ovarian cancer, and uncover new methods of treatment for this disease.

\section{REFERENCES}

1. McGuire WP III, Markman M. Primary ovarian cancer chemotherapy: current standards of care. Br J Cancer (2003) 89(Suppl 3):S3-8. doi:10.1038/sj.bjc. 6601494

2. Cerami E, Gao J, Dogrusoz U, Gross BE, Sumer SO, Aksoy BA, et al. The cBio cancer genomics portal: an open platform for exploring multidimensional cancer genomics data. Cancer Discov (2012) 2(5):401-4. doi:10.1158/2159-8290. CD-12-0095

3. Gao J, Aksoy BA, Dogrusoz U, Dresdner G, Gross B, Sumer SO, et al. Integrative analysis of complex cancer genomics and clinical profiles using the cBioPortal. Sci Signal (2013) 6(269):11. doi:10.1126/scisignal.2004088

4. Yap TA, Carden CP, Kaye SB. Beyond chemotherapy: targeted therapies in ovarian cancer. Nat Rev Cancer (2009) 9(3):167-81. doi:10.1038/nrc2583

5. Sawadogo M, Roeder RG. Factors involved in specific transcription by human RNA polymerase II: analysis by a rapid and quantitative in vitro assay. Proc Natl Acad Sci U S A (1985) 82(13):4394-8. doi:10.1073/pnas.82.13.4394

6. Reinberg D, Horikoshi M, Roeder RG. Factors involved in specific transcription in mammalian RNA polymerase II. Functional analysis of initiation factors IIA and IID and identification of a new factor operating at sequences downstream of the initiation site. J Biol Chem (1987) 262(7):3322-30.

7. Dynlacht BD, Hoey T, Tjian R. Isolation of coactivators associated with the TATA-binding protein that mediate transcriptional activation. Cell (1991) 66(3):563-76. doi:10.1016/0092-8674(81)90019-2

8. Kokubo T, Gong DW, Wootton JC, Horikoshi M, Roeder RG, Nakatani Y. Molecular cloning of Drosophila TFIID subunits. Nature (1994) 367(6462):484-7. doi:10.1038/367484a0

9. Malkowska M, Kokoszynska K, Rychlewski L, Wyrwicz L. Structural bioinformatics of the general transcription factor TFIID. Biochimie (2013) 95(4):680-91. doi:10.1016/j.biochi.2012.10.024 
10. Müller FZA, Tora L. Developmental regulation of transcription initiation: more than just changing the actors. Curr Opin Genet Dev (2010) 20(5):533-40. doi:10.1016/j.gde.2010.06.004

11. Deato MD, Marr MT, Sottero T, Inouye C, Hu P, Tjian R. MyoD targets TAF3/TRF3 to activate myogenin transcription. Mol Cell (2008) 32(1):96-105. doi:10.1016/j.molcel.2008.09.009

12. Deato MD, Tjian R. Switching of the core transcription machinery during myogenesis. Genes Dev (2007) 21(17):2137-49. doi:10.1101/gad.1583407

13. Deato MD, Tjian R. An unexpected role of TAFs and TRFs in skeletal muscle differentiation: switching core promoter complexes. Cold Spring Harb Symp Quant Biol (2008) 73:217-25. doi:10.1101/sqb.2008.73.028

14. Dikstein R, Zhou S, Tjian R. Human TAFII 105 is a cell type-specific TFIID subunit related to hTAFII130. Cell (1996) 87(1):137-46. doi:10.1016/S00928674(00)81330-6

15. Martianov I, Brancorsini S, Gansmuller A, Parvinen M, Davidson I, SassoneCorsi P. Distinct functions of TBP and TLF/TRF2 during spermatogenesis: requirement of TLF for heterochromatic chromocenter formation in haploid round spermatids. Development (2002) 129(4):945-55.

16. Zhou H, Grubisic I, Zheng K, He Y, Wang PJ, Kaplan T, et al. Taf7l cooperates with Trf2 to regulate spermiogenesis. Proc Natl Acad Sci U S A (2013) 110(42):16886-91. doi:10.1073/pnas.1317034110

17. Freiman RN, Albright SR, Zheng S, Sha WC, Hammer RE, Tjian R. Requirement of tissue-selective TBP-associated factor TAFII105 in ovarian development. Science (2001) 293(5537):2084-7. doi:10.1126/science.1061935

18. Zhao S, Choi M, Overton JD, Bellone S, Roque DM, Cocco E, et al. Landscape of somatic single-nucleotide and copy-number mutations in uterine serous carcinoma. Proc Natl Acad Sci U S A (2013) 110(8):2916-21. doi:10.1073/pnas. 1222577110

19. Tavassoli P, Wafa LA, Cheng H, Zoubeidi A, Fazli L, Gleave M, et al. TAF1 differentially enhances androgen receptor transcriptional activity via its N-terminal kinase and ubiquitin-activating and -conjugating domains. Mol Endocrinol (2010) 24(4):696-708. doi:10.1210/me.2009-0229

20. Kimura J, Nguyen ST, Liu H, Taira N, Miki Y, Yoshida K. A functional genomewide RNAi screen identifies TAF1 as a regulator for apoptosis in response to genotoxic stress. Nucleic Acids Res (2008) 36(16):5250-9. doi:10.1093/nar/ gkn506

21. Centeno F, Ramirez-Salazar E, Garcia-Villa E, Gariglio P, Garrido E. TAF1 interacts with and modulates human papillomavirus 16 E2-dependent transcriptional regulation. Intervirology (2008) 51(2):137-43. doi:10.1159/000141706

22. Carrillo E, Garrido E, Gariglio P. Specific in vitro interaction between papillomavirus E2 proteins and TBP-associated factors. Intervirology (2004) 47(6):342-9. doi:10.1159/000080878

23. Allende-Vega N, Saville MK, Meek DW. Transcription factor TAFII250 promotes Mdm2-dependent turnover of p53. Oncogene (2007) 26(29):4234-42. doi:10.1038/sj.onc. 1210209

24. Li HH, Li AG, Sheppard HM, Liu X. Phosphorylation on Thr-55 by TAF1 mediates degradation of p53: a role for TAF1 in cell G1 progression. Mol Cell (2004) 13(6):867-78. doi:10.1016/S1097-2765(04)00123-6

25. Hilton TL, Li Y, Dunphy EL, Wang EH. TAF1 histone acetyltransferase activity in Sp1 activation of the cyclin D1 promoter. Mol Cell Biol (2005) 25(10):4321-32. doi:10.1128/MCB.25.10.4321-4332.2005

26. Buchmann AM, Skaar JR, DeCaprio JA. Activation of a DNA damage checkpoint response in a TAF1-defective cell line. Mol Cell Biol (2004) 24(12):5332-9. doi:10.1128/MCB.24.12.5332-5339.2004

27. Dehm SM, Hilton TL, Wang EH, Bonham K. SRC proximal and core promoter elements dictate TAF1 dependence and transcriptional repression by histone deacetylase inhibitors. Mol Cell Biol (2004) 24(6):2296-307. doi:10.1128/MCB. 24.6.2296-2307.2004

28. Bartusel T, Klempnauer KH. Transactivation mediated by B-Myb is dependent on TAF(II)250. Oncogene (2003) 22(19):2932-41. doi:10.1038/sj. onc. 1206494

29. Lively TN, Ferguson HA, Galasinski SK, Seto AG, Goodrich JA. c-Jun binds the $\mathrm{N}$ terminus of human TAF(II)250 to derepress RNA polymerase II transcription in vitro. J Biol Chem (2001) 276(27):25582-8. doi:10.1074/jbc. M100278200

30. Wang EH, Zou S, Tjian R. TAFII250-dependent transcription of cyclin A is directed by ATF activator proteins. Genes Dev (1997) 11(20):2658-69. doi:10.1101/gad.11.20.2658
31. Walker SS, Shen WC, Reese JC, Apone LM, Green MR. Yeast TAF(II) 145 required for transcription of G1/S cyclin genes and regulated by the cellular growth state. Cell (1997) 90(4):607-14. doi:10.1016/S0092-8674(00)80522-X

32. Fadloun A, Kobi D, Pointud JC, Indra AK, Teletin M, Bole-Feysot C, et al The TFIID subunit TAF4 regulates keratinocyte proliferation and has cellautonomous and non-cell-autonomous tumour suppressor activity in mouse epidermis. Development (2007) 134(16):2947-58. doi:10.1242/dev.005041

33. Wardell JR, Hodgkinson KM, Binder AK, Seymour KA, Korach KS, Vanderhyden BC, et al. Estrogen responsiveness of the TFIID subunit TAF4B in the normal mouse ovary and in ovarian tumors. Biol Reprod (2013) 89(5):116. doi:10.1095/biolreprod.113.111336

34. Jerhammar F, Ceder R, Garvin S, Grenman R, Grafstrom RC, Roberg K. Fibronectin 1 is a potential biomarker for radioresistance in head and neck squamous cell carcinoma. Cancer Biol Ther (2010) 10(12):1244-51. doi:10.4161/cbt.10.12.13432

35. Kalogeropoulou M, Voulgari A, Kostourou V, Sandaltzopoulos R, Dikstein R, Davidson I, et al. TAF4b and Jun/activating protein-1 collaborate to regulate the expression of integrin alpha6 and cancer cell migration properties. $\mathrm{Mol}$ Cancer Res (2010) 8(4):554-68. doi:10.1158/1541-7786.MCR-09-0159

36. Teye K, Okamoto K, Tanaka Y, Umata T, Ohnuma M, Moroi M, et al. Expression of the TAF4b gene is induced by MYC through a non-canonical, but not canonical, E-box which contributes to its specific response to MYC. Int J Oncol (2008) 33(6):1271-80. doi:10.3892/ijo_00000118

37. Wang W, Nahta R, Huper G, Marks JR. TAFII70 isoform-specific growth suppression correlates with its ability to complex with the GADD45a protein. Mol Cancer Res (2004) 2(8):442-52.

38. Bell B, Scheer E, Tora L. Identification of hTAF(II) 80 delta links apoptotic signaling pathways to transcription factor TFIID function. Mol Cell (2001) 8(3):591-600. doi:10.1016/S1097-2765(01)00325-2

39. Thut CJ, Chen JL, Klemm R, Tjian R. p53 transcriptional activation mediated by coactivators TAFII40 and TAFII60. Science (1995) 267(5194):100-4. doi:10.1126/science.7809597

40. Fukuchi J, Hiipakka RA, Kokontis JM, Nishimura K, Igarashi K, Liao S. TATAbinding protein-associated factor 7 regulates polyamine transport activity and polyamine analog-induced apoptosis. J Biol Chem (2004) 279(29):29921-9. doi:10.1074/jbc.M401078200

41. Munz C, Psichari E, Mandilis D, Lavigne AC, Spiliotaki M, Oehler T, et al. TAF7 (TAFII55) plays a role in the transcription activation by c-Jun. J Biol Chem (2003) 278(24):21510-6. doi:10.1074/jbc.M212764200

42. Yazarloo F, Shirkoohi R, Mobasheri MB, Emami A, Modarressi MH. Expression analysis of four testis-specific genes AURKC, OIP5, PIWIL2 and TAF7L in acute myeloid leukemia: a gender-dependent expression pattern. Med Oncol (2013) 30(1):368. doi:10.1007/s12032-012-0368-8

43. Bosco-Clement G, Zhang F, Chen Z, Zhou HM, Li H, Mikami I, et al. Targeting Gli transcription activation by small molecule suppresses tumor growth. Oncogene (2013). doi:10.1038/onc.2013.164

44. Jabbur JR, Tabor AD, Cheng X, Wang H, Uesugi M, Lozano G, et al. Mdm-2 binding and TAF(II) 31 recruitment is regulated by hydrogen bond disruption between the p53 residues Thr18 and Asp21. Oncogene (2002) 21(46):7100-13. doi:10.1038/sj.onc.1205856

45. Buschmann T, Lin Y, Aithmitti N, Fuchs SY, Lu H, Resnick-Silverman L, et al. Stabilization and activation of p53 by the coactivator protein TAFII31. J Biol Chem (2001) 276(17):13852-7. doi:10.1074/jbc.M007955200

46. $\mathrm{Lu} \mathrm{H}$, Levine AJ. Human TAFII31 protein is a transcriptional coactivator of the p53 protein. Proc Natl Acad Sci U S A (1995) 92(11):5154-8. doi:10.1073/pnas.92.11.5154

47. Verrier CS, Roodi N, Yee CJ, Bailey LR, Jensen RA, Bustin M, et al. Highmobility group (HMG) protein HMG-1 and TATA-binding protein-associated factor TAF(II)30 affect estrogen receptor-mediated transcriptional activation. Mol Endocrinol (1997) 11(8):1009-19. doi:10.1210/mend.11.8.9962

48. Voulgari A, Voskou S, Tora L, Davidson I, Sasazuki T, Shirasawa S, et al. TATA box-binding protein-associated factor 12 is important for RAS-induced transformation properties of colorectal cancer cells. Mol Cancer Res (2008) 6(6):1071-83. doi:10.1158/1541-7786.MCR-07-0375

49. Cancer Genome Atlas Research Network. Integrated genomic analyses of ovarian carcinoma. Nature (2011) 474(7353):609-15. doi:10.1038/nature10166

50. Brunkhorst A, Karlen M, Shi J, Mikolajczyk M, Nelson MA, Metsis M, et al. A specific role for the TFIID subunit TAF4 and RanBPM in neural progenitor 
differentiation. Mol Cell Neurosci (2005) 29(2):250-8. doi:10.1016/j.mcn.2005. 02.015

51. Indra AK, Mohan WS II, Frontini M, Scheer E, Messaddeq N, Metzger D, et al. TAF10 is required for the establishment of skin barrier function in foetal, but not in adult mouse epidermis. Dev Biol (2005) 285(1):28-37. doi:10.1016/j.ydbio.2005.05.043

52. Iwata J, Hosokawa R, Sanchez-Lara PA, Urata M, Slavkin H, Chai Y. Transforming growth factor-beta regulates basal transcriptional regulatory machinery to control cell proliferation and differentiation in cranial neural crest-derived osteoprogenitor cells. J Biol Chem (2010) 285(7):4975-82. doi:10.1074/jbc. M109.035105

53. D'Alessio JA, Ng R, Willenbring H, Tjian R. Core promoter recognition complex changes accompany liver development. Proc Natl Acad Sci U S A (2011) 108(10):3906-11. doi:10.1073/pnas.1100640108

54. Liu Z, Scannell DR, Eisen MB, Tjian R. Control of embryonic stem cell lineage commitment by core promoter factor, TAF3. Cell (2011) 146(5):720-31. doi:10.1016/j.cell.2011.08.005

55. Bahat A, Kedmi R, Gazit K, Richardo-Lax I, Ainbinder E, Dikstein R. TAF4b and TAF4 differentially regulate mouse embryonic stem cells maintenance and proliferation. Genes Cells (2013) 18(3):225-37. doi:10.1111/gtc.12030

56. Mengus G, Fadloun A, Kobi D, Thibault C, Perletti L, Michel I, et al. TAF4 inactivation in embryonic fibroblasts activates TGF beta signalling and autocrine growth. EMBO J (2005) 24(15):2753-67. doi:10.1038/sj.emboj.7600748

57. PijnappelWW, Esch D, Baltissen MP, Wu G, Mischerikow N, Bergsma AJ, et al. A central role for TFIID in the pluripotent transcription circuitry. Nature (2013) 495(7442):516-9. doi:10.1038/nature11970

58. Kazantseva J, Kivil A, Tints K, Kazantseva A, Neuman T, Palm K. Alternative splicing targeting the hTAF4-TAFH domain of TAF4 represses proliferation and accelerates chondrogenic differentiation of human mesenchymal stem cells. PLoS One (2013) 8(10):e74799. doi:10.1371/journal.pone.0074799

59. Greene AK, Puder M. Partial hepatectomy in the mouse: technique and perioperative management. J Invest Surg (2003) 16(2):99-102. doi:10.1080/ 08941930390194424

60. Tantin D, Gemberling M, Callister C, Fairbrother WG. High-throughput biochemical analysis of in vivo location data reveals novel distinct classes of POU5F1(Oct4)/DNA complexes. Genome Res (2008) 18(4):631-9. doi:10. 1101/gr.072942.107

61. Lovasco LA, Seymour KA, Zafra K, O'Brien CW, Schorl C, Freiman RN. Accelerated ovarian aging in the absence of the transcription regulator TAF4B in mice. Biol Reprod (2010) 82(1):23-34. doi:10.1095/biolreprod.109. 077495

62. Voronina E, Lovasco LA, Gyuris A, Baumgartner RA, Parlow AF, Freiman RN. Ovarian granulosa cell survival and proliferation requires the gonad-selective TFIID subunit TAF4b. Dev Biol (2007) 303(2):715-26. doi:10.1016/j.ydbio. 2006.12.011

63. Auersperg N. Ovarian surface epithelium as a source of ovarian cancers: unwarranted speculation or evidence-based hypothesis? Gynecol Oncol (2013) 130(1):246-51. doi:10.1016/j.ygyno.2013.03.021

64. Dubeau L, Drapkin R. Coming into focus: the nonovarian origins of ovarian cancer. Ann Oncol (2013) 24(Suppl 8):viii28-35. doi:10.1093/annonc/mdt308

65. Giles JR, Shivaprasad HL, Johnson PA. Ovarian tumor expression of an oviductal protein in the hen: a model for human serous ovarian adenocarcinoma. Gynecol Oncol (2004) 95(3):530-3. doi:10.1016/j.ygyno.2004.07.061

66. Laviolette LA, Garson K, Macdonald EA, Senterman MK, Courville K, Crane CA, et al. 17Beta-estradiol accelerates tumor onset and decreases survival in a transgenic mouse model of ovarian cancer. Endocrinology (2010) 151(3):929-38. doi:10.1210/en.2009-0602

67. Connolly DC, Bao R, Nikitin AY, Stephens KC, Poole TW, Hua X, et al. Female mice chimeric for expression of the simian virus $40 \mathrm{TAg}$ under control of the MISIIR promoter develop epithelial ovarian cancer. Cancer Res (2003) 63(6):1389-97.

68. Flesken-Nikitin A, Choi KC, Eng JP, Shmidt EN, Nikitin AY. Induction of carcinogenesis by concurrent inactivation of $\mathrm{p} 53$ and $\mathrm{Rb} 1$ in the mouse ovarian surface epithelium. Cancer Res (2003) 63(13):3459-63.

69. Flesken-Nikitin A, Hwang CI, Cheng CY, Michurina TV, Enikolopov G, Nikitin AY. Ovarian surface epithelium at the junction area contains a cancer-prone stem cell niche. Nature (2013) 495(7440):241-5. doi:10.1038/ nature11979
70. Hakim AA, Barry CP, Barnes HJ, Anderson KE, Petitte J, Whitaker R, et al. Ovarian adenocarcinomas in the laying hen and women share similar alterations in p53, ras, and HER-2/neu. Cancer Prev Res (Phila) (2009) 2(2):114-21. doi:10.1158/1940-6207.CAPR-08-0065

71. Gabbert H, Wagner R, Moll R, Gerharz CD. Tumor dedifferentiation: an important step in tumor invasion. Clin Exp Metastasis (1985) 3(4):257-79. doi:10.1007/BF01585081

72. Sakuragi N, Nishiya M, Ikeda K, Ohkouch T, Furth EE, Hareyama H, et al. Decreased E-cadherin expression in endometrial carcinoma is associated with tumor dedifferentiation and deep myometrial invasion. Gynecol Oncol (1994) 53(2):183-9. doi:10.1006/gyno.1994.1113

73. Schipper JH, Frixen UH, Behrens J, Unger A, Jahnke K, Birchmeier W. Ecadherin expression in squamous cell carcinomas of head and neck: inverse correlation with tumor dedifferentiation and lymph node metastasis. Cancer Res (1991) 51(23 Pt 1):6328-37.

74. Gamallo C, Palacios J, Suarez A, Pizarro A, Navarro P, Quintanilla M, et al. Correlation of E-cadherin expression with differentiation grade and histological type in breast carcinoma. Am J Pathol (1993) 142(4):987-93.

75. Bodurka DC, Deavers MT, Tian C, Sun CC, Malpica A, Coleman RL, et al. Reclassification of serous ovarian carcinoma by a 2-tier system: a Gynecologic Oncology Group Study. Cancer (2012) 118(12):3087-94. doi:10.1002/ cncr.26618

76. Liu D, Huang C, Kameyama K, Hayashi E, Yamauchi A, Kobayashi S, et al. Ecadherin expression associated with differentiation and prognosis in patients with non-small cell lung cancer. Ann Thorac Surg (2001) 71(3):949-54. doi:10.1016/S0003-4975(00)02545-5

77. Tamura S, Shiozaki H, Miyata M, Kadowaki T, Inoue M, Matsui S, et al. Decreased E-cadherin expression is associated with haematogenous recurrence and poor prognosis in patients with squamous cell carcinoma of the oesophagus. Br J Surg (1996) 83(11):1608-14. doi:10.1002/bjs.1800831138

78. Fujita S, Shimoda T, Yoshimura K, Yamamoto S, Akasu T, Moriya Y. Prospective evaluation of prognostic factors in patients with colorectal cancer undergoing curative resection. J Surg Oncol (2003) 84(3):127-31. doi:10.1002/jso.10308

79. Siitonen SM, Kononen JT, Helin HJ, Rantala IS, Holli KA, Isola JJ. Reduced Ecadherin expression is associated with invasiveness and unfavorable prognosis in breast cancer. Am J Clin Pathol (1996) 105(4):394-402.

80. Huang RY, Chung VY, Thiery JP. Targeting pathways contributing to epithelialmesenchymal transition (EMT) in epithelial ovarian cancer. Curr Drug Targets (2012) 13(13):1649-53. doi:10.2174/138945012803530044

81. Borgfeldt C, Hansson SR, Gustavsson B, Masback A, Casslen B. Dedifferentiation of serous ovarian cancer from cystic to solid tumors is associated with increased expression of mRNA for urokinase plasminogen activator (uPA), its receptor (uPAR) and its inhibitor (PAI-1). Int J Cancer (2001) 92(4):497-502. doi:10.1002/ijc. 1215

82. Davies BR, Worsley SD, Ponder BA. Expression of E-cadherin, alpha-catenin and beta-catenin in normal ovarian surface epithelium and epithelial ovarian cancers. Histopathology (1998) 32(1):69-80. doi:10.1046/j.1365-2559.1998. 00341.x

83. Veatch AL, Carson LF, Ramakrishnan S. Differential expression of the cell-cell adhesion molecule E-cadherin in ascites and solid human ovarian tumor cells. Int J Cancer (1994) 58(3):393-9. doi:10.1002/ijc.2910580315

84. Fujioka T, Takebayashi Y, Kihana T, Kusanagi Y, Hamada K, Ochi H, et al. Expression of E-cadherin and beta-catenin in primary and peritoneal metastatic ovarian carcinoma. Oncol Rep (2001) 8(2):249-55.

85. Sundfeldt K. Cell-cell adhesion in the normal ovary and ovarian tumors of epithelial origin; an exception to the rule. Mol Cell Endocrinol (2003) 202(12):89-96. doi:10.1016/S0303-7207(03)00068-6

86. Rask K, Nilsson A, Brannstrom M, Carlsson P, Hellberg P, Janson PO, et al. Wnt-signalling pathway in ovarian epithelial tumours: increased expression of beta-catenin and GSK3beta. Br J Cancer (2003) 89(7):1298-304. doi:10.1038/sj.bjc.6601265

87. Zhang S, Balch C, Chan MW, Lai HC, Matei D, Schilder JM, et al. Identification and characterization of ovarian cancer-initiating cells from primary human tumors. Cancer Res (2008) 68(11):4311-20. doi:10.1158/0008-5472.CAN-080364

88. Wang ML, Chiou SH, Wu CW. Targeting cancer stem cells: emerging role of Nanog transcription factor. Onco Targets Ther (2013) 6:1207-20. doi:10.2147/ OTT.S38114 
89. Lopez J, Valdez-Morales FJ, Benitez-Bribiesca L, Cerbon M, Carranca AG. Normal and cancer stem cells of the human female reproductive system. Reprod Biol Endocrinol (2013) 11:53. doi:10.1186/1477-7827-11-53

90. Alvero AB, Chen R, Fu HH, Montagna M, Schwartz PE, Rutherford T, et al. Molecular phenotyping of human ovarian cancer stem cells unravels the mechanisms for repair and chemoresistance. Cell Cycle (2009) 8(1):158-66. doi:10.4161/cc.8.1.7533

91. Meng E, Long B, Sullivan P, McClellan S, Finan MA, Reed E, et al. CD44+/CD24- ovarian cancer cells demonstrate cancer stem cell properties and correlate to survival. Clin Exp Metastasis (2012) 29(8):939-48. doi:10.1007/s10585-012-9482-4

92. Yasuda K, Torigoe T, Morita R, Kuroda T, Takahashi A, Matsuzaki J, et al. Ovarian cancer stem cells are enriched in side population and aldehyde dehydrogenase bright overlapping population. PLoS One (2013) 8(8):e68187. doi:10.1371/journal.pone.0068187

93. Kryczek I, Liu S, Roh M, Vatan L, Szeliga W, Wei S, et al. Expression of aldehyde dehydrogenase and CD133 defines ovarian cancer stem cells. Int J Cancer (2012) 130(1):29-39. doi:10.1002/ijc.25967

94. Silva IA, Bai S, McLean K, Yang K, Griffith K, Thomas D, et al. Aldehyde dehydrogenase in combination with CD133 defines angiogenic ovarian cancer stem cells that portend poor patient survival. Cancer Res (2011) 71(11):3991-4001. doi:10.1158/0008-5472.CAN-10-3175

95. Metzger D, Scheer E, Soldatov A, Tora L. Mammalian TAF(II)30 is required for cell cycle progression and specific cellular differentiation programmes. $E M B O$ $J$ (1999) 18(17):4823-34. doi:10.1093/emboj/18.17.4823

96. Chalkley GE, Verrijzer CP. DNA binding site selection by RNA polymerase II TAFs: a TAF(II)250-TAF(II) 150 complex recognizes the initiator. EMBO J (1999) 18(17):4835-45. doi:10.1093/emboj/18.17.4835

97. Martinez E, Zhou Q, L'Etoile ND, Oelgeschlager T, Berk AJ, Roeder RG. Core promoter-specific function of a mutant transcription factor TFIID defective in TATA-box binding. Proc Natl Acad Sci U S A (1995) 92(25):11864-8. doi:10.1073/pnas.92.25.11864

98. Wright KJ, Marr MT II, Tjian R. TAF4 nucleates a core subcomplex of TFIID and mediates activated transcription from a TATA-less promoter. Proc Natl Acad Sci U S A (2006) 103(33):12347-52. doi:10.1073/pnas.0605499103

99. Wieczorek E, Brand M, Jacq X, Tora L. Function of TAF(II)-containing complex without TBP in transcription by RNA polymerase II. Nature (1998) 393(6681):187-91. doi:10.1038/30283

100. Simpkins F, Hevia-Paez P, Sun J, Ullmer W, Gilbert CA, da Silva T, et al. Src inhibition with saracatinib reverses fulvestrant resistance in ER-positive ovarian cancer models in vitro and in vivo. Clin Cancer Res (2012) 18(21):5911-23. doi:10.1158/1078-0432.CCR-12-1257

101. Wiener JR, Windham TC, Estrella VC, Parikh NU, Thall PF, Deavers MT, et al. Activated SRC protein tyrosine kinase is overexpressed in late-stage human ovarian cancers. Gynecol Oncol (2003) 88(1):73-9. doi:10.1006/gyno.2002. 6851

102. Song RX, Barnes CJ, Zhang Z, Bao Y, Kumar R, Santen RJ. The role of Shc and insulin-like growth factor 1 receptor in mediating the translocation of estrogen receptor alpha to the plasma membrane. Proc Natl Acad Sci U S A (2004) 101(7):2076-81. doi:10.1073/pnas.0308334100

103. Filardo EJ, Thomas P. Minireview: G protein-coupled estrogen receptor1, GPER-1: its mechanism of action and role in female reproductive cancer, renal and vascular physiology. Endocrinology (2012) 153(7):2953-62. doi:10.1210/en.2012-1061

104. Johnson SA, Dubeau L, Kawalek M, Dervan A, Schonthal AH, Dang CV, et al. Increased expression of TATA-binding protein, the central transcription factor, can contribute to oncogenesis. Mol Cell Biol (2003) 23(9):3043-51. doi:10.1128/MCB.23.9.3043-3051.2003

105. Soe KC, Devaiah BN, Singer DS. Transcriptional coactivator CIITA, a functional homolog of TAF1, has kinase activity. Biochim Biophys Acta (2013) 1829(11):1184-90. doi:10.1016/j.bbagrm.2013.09.001

106. Sekiguchi T, Nishimoto T, Hunter T. Overexpression of D-type cyclins, E2F-1, SV40 large T antigen and HPV16 E7 rescue cell cycle arrest of tsBN462 cells caused by the CCG1/TAF(II)250 mutation. Oncogene (1999) 18(10):1797-806. doi:10.1038/sj.onc. 1202508

107. O'Brien T, Tjian R. Functional analysis of the human TAFII250 N-terminal kinase domain. Mol Cell (1998) 1(6):905-11. doi:10.1016/S1097-2765(00) 80089- 1
108. Falender AE, Shimada M, Lo YK, Richards JS. TAF4b, a TBP associated factor, is required for oocyte development and function. Dev Biol (2005) 288(2):405-19. doi:10.1016/j.ydbio.2005.09.038

109. Wang C, Lv X, Jiang C, Cordes CM, Fu L, Lele SM, et al. Transforming growth factor alpha (TGFalpha) regulates granulosa cell tumor (GCT) cell proliferation and migration through activation of multiple pathways. PLoS One (2012) 7(11):e48299. doi:10.1371/journal.pone.0048299

110. Geles KG, Freiman RN, Liu WL, Zheng S, Voronina E, Tjian R. Cell-typeselective induction of c-jun by TAF4b directs ovarian-specific transcription networks. Proc Natl Acad Sci U S A (2006) 103(8):2594-9. doi:10.1073/pnas. 0510764103

111. Liu WL, Coleman RA, Grob P, King DS, Florens L, Washburn MP, et al. Structural changes in TAF4b-TFIID correlate with promoter selectivity. Mol Cell (2008) 29(1):81-91. doi:10.1016/j.molcel.2007.11.003

112. Jamieson S, Fuller PJ. Molecular pathogenesis of granulosa cell tumors of the ovary. Endocr Rev (2012) 33(1):109-44. doi:10.1210/er.2011-0014

113. Gulliver LS, Hurst PR. Repeat estradiol exposure differentially regulates protein expression patterns for estrogen receptor and E-cadherin in older mouse ovarian surface epithelium: implications for replacement and adjuvant hormone therapies? Steroids (2012) 77(6):674-85. doi:10.1016/j.steroids.2012. 02.015

114. Okamura H, Katabuchi H, Nitta M, Ohtake H. Structural changes and cell properties of human ovarian surface epithelium in ovarian pathophysiology. Microsc Res Tech (2006) 69(6):469-81. doi:10.1002/jemt.20306

115. Riman T, Dickman PW, Nilsson S, Correia N, Nordlinder H, Magnusson $\mathrm{CM}$, et al. Risk factors for invasive epithelial ovarian cancer: results from a Swedish case-control study. Am J Epidemiol (2002) 156(4):363-73. doi:10.1093/aje/kwf048

116. Garg PP, Kerlikowske K, Subak L, Grady D. Hormone replacement therapy and the risk of epithelial ovarian carcinoma: a meta-analysis. Obstet Gynecol (1998) 92(3):472-9. doi:10.1016/S0029-7844(98)00139-2

117. Lacey JV Jr, Mink PJ, Lubin JH, Sherman ME, Troisi R, Hartge P, et al. Menopausal hormone replacement therapy and risk of ovarian cancer. JAMA (2002) 288(3):334-41. doi:10.1001/jama.288.3.334

118. Anderson GL, Judd HL, Kaunitz AM, Barad DH, Beresford SA, Pettinger M, et al. Effects of estrogen plus progestin on gynecologic cancers and associated diagnostic procedures: the women's health initiative randomized trial. JAMA (2003) 290(13):1739-48. doi:10.1001/jama.290.13.1739

119. Beral V, Bull D, Green J, Reeves G. Ovarian cancer and hormone replacement therapy in the Million Women Study. Lancet (2007) 369(9574):1703-10. doi:10.1016/S0140-6736(07)60534-0

120. Rodriguez C, Patel AV, Calle EE, Jacob EJ, Thun MJ. Estrogen replacement therapy and ovarian cancer mortality in a large prospective study of US women. JAMA (2001) 285(11):1460-5. doi:10.1001/jama.285.11.1460

121. Yamit-Hezi A, Dikstein R. TAFII105 mediates activation of anti-apoptotic genes by NF-kappaB. EMBO J (1998) 17(17):5161-9. doi:10.1093/emboj/17. 17.5161

122. Silkov A, Wolstein O, Shachar I, Dikstein R. Enhanced apoptosis of B and T lymphocytes in TAFII105 dominant-negative transgenic mice is linked to nuclear factor-kappa B. J Biol Chem (2002) 277(20):17821-9. doi:10.1074/jbc. M200696200

123. Diamant G, Dikstein R. Transcriptional control by NF-kappaB: elongation in focus. Biochim Biophys Acta (2013) 1829(9):937-45. doi:10.1016/j.bbagrm. 2013.04.007

124. Aoki T, Koike T, Nakano T, Shibahara K, Nishimura H, Kikuchi H, et al. Rat TAFII31 gene is induced upon programmed cell death in differentiated PC12 cells deprived of NGF. Biochem Biophys Res Commun (1997) 234(1):230-4. doi:10.1006/bbrc.1997.6610

125. Vang R, Shih Ie M, Kurman RJ. Ovarian low-grade and high-grade serous carcinoma: pathogenesis, clinicopathologic and molecular biologic features, and diagnostic problems. Adv Anat Pathol (2009) 16(5):267-82. doi:10.1097/PAP. 0b013e3181b4fffa

126. Tan DS, Miller RE, Kaye SB. New perspectives on molecular targeted therapy in ovarian clear cell carcinoma. Br J Cancer (2013) 108(8):1553-9. doi:10.1038/bjc.2013.126

127. Davidson I, Kobi D, Fadloun A, Mengus G. New insights into TAFs as regulators of cell cycle and signaling pathways. Cell Cycle (2005) 4(11):1486-90. doi:10.4161/cc.4.11.2120 
128. Comai L, Tanese N, Tjian R. The TATA-binding protein and associated factors are integral components of the RNA polymerase I transcription factor, SL1. Cell (1992) 68(5):965-76. doi:10.1016/0092-8674(92)90039-F

129. Taggart AK, Fisher TS, Pugh BF. The TATA-binding protein and associated factors are components of pol III transcription factor TFIIIB. Cell (1992) 71(6):1015-28. doi:10.1016/0092-8674(92)90396-T

130. Johnson SA, Dubeau L, White RJ, Johnson DL. The TATA-binding protein as a regulator of cellular transformation. Cell Cycle (2003) 2(5):442-4. doi:10.4161/cc.2.5.493

Conflict of Interest Statement: The authors declare that the research was conducted in the absence of any commercial or financial relationships that could be construed as a potential conflict of interest.
Received: 09 January 2014; accepted: 25 February 2014; published online: 11 March 2014.

Citation: Ribeiro JR, Lovasco LA, Vanderhyden BC and Freiman RN (2014) Targeting TBP-associated factors in ovarian cancer. Front. Oncol. 4:45. doi: 10.3389/fonc.2014.00045

This article was submitted to Women's Cancer, a section of the journal Frontiers in Oncology.

Copyright (c) 2014 Ribeiro, Lovasco, Vanderhyden and Freiman. This is an open-access article distributed under the terms of the Creative Commons Attribution License (CC $B Y)$. The use, distribution or reproduction in other forums is permitted, provided the original author(s) or licensor are credited and that the original publication in this journal is cited, in accordance with accepted academic practice. No use, distribution or reproduction is permitted which does not comply with these terms. 